\title{
Neurophysiologie de la douleur
}

C Springer-Verlag France 2010

Nociceptives, neuropathiques, cancéreuses, viscérales... il n'y a pas « une » mais « des » douleurs. Ce caractère multiple implique une observation minutieuse des mécanismes qui la génèrent afin de donner au patient un traitement antalgique optimal. Tout l'enjeu réside donc dans l'étude de ces mécanismes.

Dans cette nouvelle parution de la lettre «La douleur, des recommandations à la pratique " éditée par l'institut UPSA de la douleur, les Drs Francine Hirszowski et Sylvie Rostaing nous livrent une étude sur le mécanisme des douleurs nociceptives et neuropathiques mais aussi sur le mécanisme physiopathologique des douleurs cancéreuses.

Le Dr Florentin Clère rend compte des actualités au sujet de la physiopathologie des douleurs viscérales gastro-intestinales en expliquant les raisons des difficultés rencontrées pour leur prise en charge, mais aussi en étudiant deux facteurs principaux de développement des syndromes douloureux.

La douleur étant multiple, un remaniement autour de la définition taxonomique de la douleur neuropathique est nécessaire. Le Dr Virginie Guastella se propose donc de partir de la naissance du terme " douleur neuropathique », d'observer la nouvelle définition de ce terme pour l'envisager enfin au travers d'un cas pratique.

Cette publication est disponible sur le site Internet de l'institut :

www.institut-upsa-douleur.org

Conflit d'intérêt : aucun.

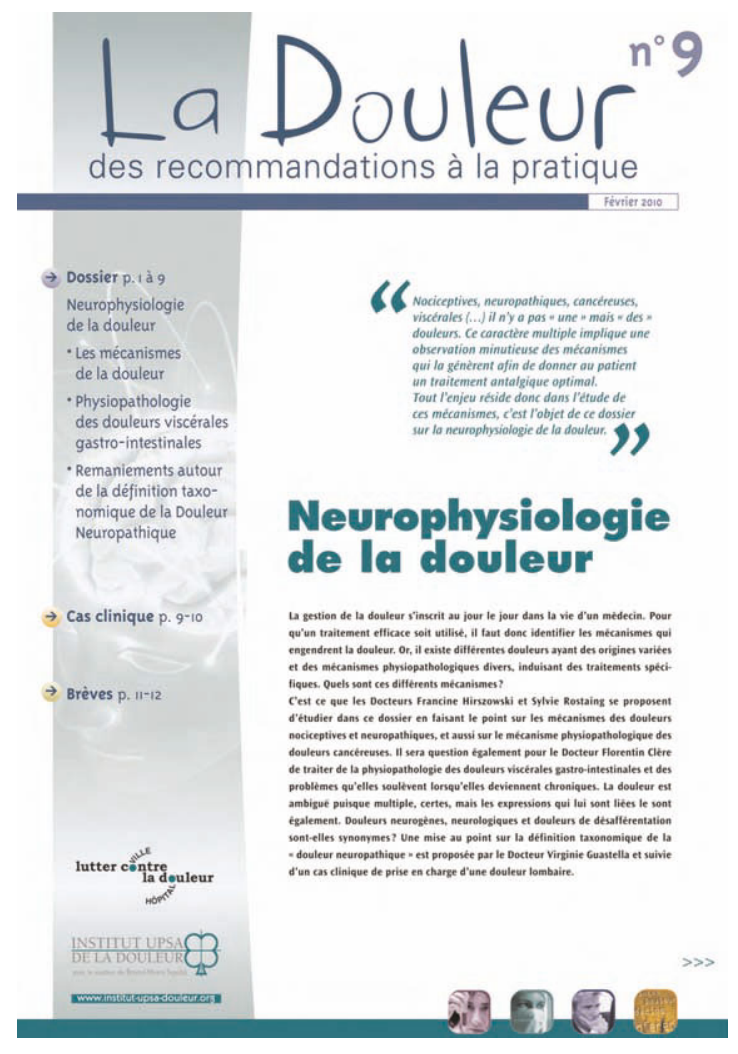

